\title{
PROCESSO CIVIL VIRTUAL: ENTRE A EFETIVIDADE E A CELERIDADE
}

\author{
Leticia Nascimbem Colovati ${ }^{1}$ \\ Renata Carrara Bussab ${ }^{2}$
}

\section{RESUMO}

O presente trabalho tem por objetivo estudar os avanços da tecnologia, e sua consequente contribuição no âmbito do Poder Judiciário, e, por conseguinte, do Processo Civil. A abordagem inicial realizar-se-á pelo método hipotético-dedutivo, trazendo questões importantes sobre a modernização do Judiciário, e da legislação, com previsão dos avanços nas normas jurídicas, sob pesquisa de revisão bibliográfica. Ademais, apontar-se-ão questões práticas, sob método empírico, acerca da realização de atos processuais por meio do aplicativo WhatsApp, garantindo ao jurisdicionado o efetivo exercício do direito fundamental do acesso à justiça, tendo como ponto de partida os dispositivos do Novo Código de Processo Civil.

Palavra-chave: Acesso à justiça. Tecnologia. Modernização. Efetividade. Celeridade.

\section{VIRTUAL CIVIL PROCEDURE: BETWEEN EFFECTIVENESS AND CELERITY}

\begin{abstract}
The study aims to study the advances of technology, and its consequent contribution in the scope of the Judiciary, and, Civil Procedure. The initial approach will be carried out by the hypothetical-deductive method, bringing important questions about the modernization of the Judiciary, and legislation with anticipation of advances in legal norms, under bibliographic review research. Practical questions will be set out, under an empirical method, about the performance of procedural acts through the WhatsApp application, guaranteeing to the jurisdiction the exercise of the fundamental right of access to justice, starting with the provisions of the New Code of Civil Procedure.
\end{abstract}

Keywords: Access to justice. Technology. Modernization. Effectiveness. Celerity.

\section{INTRODUÇÃO}

A busca incessante por uma prestação jurisdicional rápida e eficaz desencadeou o surgimento de mecanismos necessários ao prestígio da tutela adequada e dos direitos e garantias fundamentais.

Nessa óptica é que surge a discussão acerca da viabilidade de adoção e aplicação do processo virtual e suas ramificações.

A questão da morosidade do Judiciário é discutida desde quando o Estado proibiu a autotutela e chamou para si a responsabilidade de resolver os diversos conflitos de interesses

\footnotetext{
${ }^{1}$ Mestranda em Sistema Constitucional de Garantia de Direitos - Centro Universitário de Bauru, mantido pela Instituição Toledo de Ensino - ITE/Bauru, Advogada.

${ }^{2}$ Mestranda em Sistema Constitucional de Garantia de Direitos - Centro Universitário de Bauru, mantido pela Instituição Toledo de Ensino - ITE/Bauru, Advogada.
} 
existentes na sociedade, assumindo, para com todos, o compromisso de tornar realidade a previsão contida nas normas por ele mesmo editadas.

Não é necessário grande esforço para perceber que as medidas lançadas em nosso ordenamento não foram suficientes para tutelar/assegurar de forma célere os direitos do cidadão.

A excessiva formalidade do processo ordinário "nivelou" o tratamento entre as partes, sem levar em conta a situação fática, acarretando em muitas das vezes em uma prestação jurisdicional inócua.

Sabendo disso, inúmeras medidas foram despendidas no decorrer dos anos, na tentativa de tornar o processo mais célere, eficaz e principalmente acessível à ordem jurídica justa, tais como a antecipação da tutela e o redimensionamento do agravo de instrumento, dentre outros.

O legislador, no dever constitucional de concretização dos direitos e garantias fundamentais, promulga a Emenda Constitucional 45/2004, que introduziu, dentre outras importantes questões, o inciso LXXVIII ao rol do art. $5^{\circ}$ da Constituição Federal, garantindo a todos os cidadãos a celeridade processual, tanto em âmbito judicial quanto administrativo.

O próprio Código de Processo de 1973, desde sua vigência, passou por inúmeras reformas, tentando minimizar o tempo, apontando como exemplo a inclusão das tutelas no procedimento ordinário em 1994, o sincretismo em 2005, dentre outras tantas, a fim de adequar-se à realidade social.

Aliado a isso, tem-se o incessante avanço da tecnologia e de suas versáteis e quase universais ferramentas, não tendo passado o Direito incólume a sua influência, tal qual demonstra a adoção, no Brasil, do processo digital; entretanto, alguns atos dele derivados ainda são feitos de modo tradicional, situação essa que, muitas vezes, atravanca a celeridade do veículo eletrônico.

Nesse caminhar, a discussão que se travará neste artigo, levando-se em conta, inclusive, a estruturação do Novo Código Processual, é descobrir-se se realmente houve benefício ao jurisdicionado, em tendo sido conferida ao Poder Judiciário a possibilidade de resolução célere e justa de conflitos, perpassando, também, pela análise da aplicação de ferramentas virtuais na conclusão de atos processuais, em especial intimações e/ou notificações de atos processuais por intermédio de email-s e do WhatsApp.

A adoção de tais mecanismos poderia nascer pela composição entre as partes (negócio jurídico processual), pela imposição do juiz, pela normatização, ou ambas? 
Insiste-se, pois, que o objetivo principal do presente trabalho é estudar, sob método hipotético-dedutivo, o espaço positivo que a tecnologia vem ganhando dentro do ambiente judicial, o qual, sob pena de tornar-se obsoleto ou ultrapassado, precisa se adequar a ela.

Realizar-se-ão pesquisas, por meio da análise bibliográfica, no intuito de corroborar se um dos principais pontos de inovação da tecnologia dentro do Poder Judiciário, qual seja, a já mencionada vinda do processo digital, contribuiu à real promoção do direito fundamental do acesso à uma justa ordem jurídica pelos cidadãos.

\section{O AVANÇO DA TECNOLOGIA E A MODERNIZAÇÃO DO JUDICIÁRIO}

Analisando-se o comportamento social, notório o fato de que houve uma evolução, ou melhor, uma transformação radical influenciando, decisivamente, na conduta dos membros da sociedade.

Tornou-se, com o passar do tempo, uma sociedade ainda mais complexa, necessitando readequar todas as questões que envolvessem as relações interpessoais na era da sociedade da informação.

O primeiro grande impacto na comunicação nasceu concomitantemente ao advento da escrita, vez que as pessoas dialogavam, outrora, apenas e tão somente, de forma pessoal, passando a corresponderem-se pelo envio de cartas, circunstância essa que, mesmo podendo demorar dias, meses e até anos para que a informação pudesse chegar ao destinatário final, abreviou e acelerou o contato entre indivíduos.

Na contemporaneidade, a utilização de ferramentas virtuais tornou-se imprescindível, pois o mundo literalmente vive conectado na rede mundial de computadores, recebendo e transmitindo informações, compartilhando ideias, realizando compras, trabalhando, tudo em apenas um "click".

Nesta senda, tem-se que o século XX contribuiu, consideravelmente, na evolução das tecnologias, das facilitações da comunicação à distância e em massa (em grande escala), da mídia e da sociedade como um todo.

Em se fazendo uma breve análise, desde o rádio até a internet e a vinda de smartphones, tablets e outros, não há dúvidas de que houve uma facilitação indistinta do acesso à informação (não necessariamente de qualidade).

$\mathrm{Na}$ área acadêmica, por exemplo, os mecanismos virtuais contribuíram muito para incrementar e avançar em pesquisas, além de serem ótimas formas para aprimorar a própria 
aprendizagem.

No sentir de Patricia Peck Pinheiro (2016, p.70), tem-se que:

Globalmente, a presença da tecnologia passa a ser um novo fator de análise de subdesenvolvimento, ao mesmo tempo que equipara países que ainda não resolveram problemas primários, como saneamento básico e saúde, a outros em que essas questões já estão satisfatoriamente resolvidas.

No âmbito profissional, a utilização da internet e redes sociais atualmente servem de utilitários para empresas que fazem contatos e fecham contratos com clientes e, até mesmo, armazenam seus documentos virtuais nas chamadas "nuvens".

Essa situação contribuiu inclusive para o aumento e sucesso do empreendedorismo, já que hoje é possível se falar em empresas e grandes escritórios puramente virtuais, com comunicação e fluxo de trabalho feitos por meio de programas virtuais e redes sociais.

A era da globalização, segundo Bauman (1999, p. 7) “[...] se transforma rapidamente em um lema, uma encantação mágica, uma senha capaz de abrir as portas de todos os mistérios presentes e futuros."

Nesse contexto, também não poderia ser diferente na seara jurídica, invocando-se, uma vez mais, a profícua lição de Patricia Peck Pinheiro (2016, p. 563):

\footnotetext{
A complexidade da sociedade traz maior complexidade jurídica. Já não é suficiente conhecer apenas o Direito e as leis; devem-se conhecer os modelos que conduzem o mundo das relações entre pessoas, empresas, mercados, Estados. A postura profissional de estrategista significa assumir um papel determinantes para a adequada condução dos negócios no mundo digital. Cabe ao profissional do Direito das os caminhos e as soluções viáveis, pensando no contexto competitivo e globalizado de um possível cliente virtual-real, convergente e multicultural.
}

Essa nova sociedade passa, diariamente, por fases evolutivas que atingem não somente os cidadãos e as empresas privadas, como também órgãos públicos, administração direta e indireta, segundo o qual "os avanços tecnológicos conduzem a uma era na qual o mundo virtual mapeará o mundo real. Todas as coisas terão identidade no ciberespaço [...]" (PESANI, 2015, p. 54).

Em uma linha evolutiva, pode-se dizer que, para o Poder Judiciário, a primeira grande revolução da sociedade, senão uma das mais impactantes, fora a utilização da máquina de escrever, e, a partir de então, as sentenças que eram escritas a mão, passaram a ser datilografadas, ganhando o jurisdicionado em agilidade e facilidade de conhecimento e entendimento da referida decisão.

Novamente o século XX foi o desencadeador dos primeiros avanços no Judiciário, onde surgiram os primeiros computadores que permearam os anos 90, o que fez com que a 
máquina de escrever perdesse seu espaço.

Pontue-se que o Poder Legislativo, no seu dever constitucional, por sua vez, também não ficou para trás, pois, com o avanço desenfreado da tecnologia, novos fatos geradores de conflitos começaram a surgir, fatos estes que nosso ordenamento jurídico jamais conjecturou que poderiam ocorrer, se fazendo necessário, então, o elo da sociedade com a era digital.

Mister ressaltar que o primeiro modelo de processo eletrônico surgiu com a Lei 10.259/2001, com a criação dos juizados especiais federais, através do acesso à internet, o que foi muito bem recepcionado pelos jurisdicionados e operadores do direito em geral, já que ocasionou, dentre outras vantagens, uma celeridade processual.

A Lei 11.280 de 16 de fevereiro de 2006 trouxe a alteração de alguns dispositivos no Código de Processo Civil de Buzaid, com a significativa alteração da forma dos atos processuais, permitindo aos tribunais " [...] disciplinar a prática e a comunicação oficial dos atos processuais por meios eletrônicos [...]”, redação incluída no parágrafo único do art. 154 daquele Código.

Essas transformações interferiram e impactaram diretamente no sistema jurídico, até chegar-se ao ápice da informatização do processo em plataformas digitais, atendendo aos anseios da sociedade por uma facilitação no acesso, conforme verificar-se-á abaixo.

Dentre outras alterações do Código de Processo Civil, o marco histórico da informatização em âmbito estadual deu-se por meio da Lei 11.419, de 19 de dezembro de 2006, que instituiu, em âmbito federal, a admissão do uso eletrônico na tramitação dos processos judiciais (art. $1^{\circ}$ ), aplicando-se a todo ordenamento jurídico, indistintamente “[...] aos processos civil, penal e trabalhista, bem como aos juizados especiais, em qualquer grau de jurisdição" (art. $\left.1^{\circ}, \S 1^{\circ}\right)$, com a promoção de maior segurança. De acordo com Andréia Rocha Feitosa (2015, p.24):

A importância da certificação digital [...] haveria promoção maior, pois os códigos inseridos seriam dificilmente corrompidos. Além disso, a validade do certificado é de três anos, justamente para se evitar que uma nova tecnologia fosse descoberta, o que poderia atingir a segurança do mecanismo.

Segundo informações do próprio site do Tribunal de Justiça do Estado de São Paulo, o processo digital ganhou espaço no ano de 2006, quando o Juizado Especial Cível do Expressinho, no metrô São Bento, foi informatizado, e, em 2007, o Tribunal de Justiça de São Paulo implementou o primeiro foro digital, qual seja, o Foro Regional Nossa Senhora do Ó, com competências nas áreas Cível e de Família e Sucessões, situação que foi, posteriormente, expandida para as cidades do interior, das quais teve uma recepção calorosa pelos operadores 
do direito.

É preciso pontuar e admitir que a população não está mais adaptada a prosseguir sem o auxílio dos mecanismos digitais, em qualquer seja a esfera social, discutindo-se, sobremaneira, a necessidade de inclusão digital de todos os brasileiros.

Há facilidade nos contatos, relacionamentos, contratações de serviços, trabalhos, inclusive armazenamento de documentos digitais nas "nuvens".

Nesse contexto histórico social, e como bem pontuado anteriormente, não se pode ignorar que a era digital faça parte do mundo jurídico, sob pena de incorrer-se em estagnação das funções dos Poderes, em especial do Judiciário, além da própria sociedade.

Não mais se sustenta trabalhar, neste ciclo evolutivo digital, com a aridez e lentidão do processo físico, excetuada exceções pontuais: o caminho para um mundo inteiramente digital é sem volta!

Nesta senda, de forma a corroborar e exemplificar o transcrito acima, tem-se que dispositivos como os artigos $229, \S 2^{\circ}$ (litisconsortes terão prazo em dobro, salvo em processo digital), 236, $\S 3^{\circ}$ (prática de atos por videoconferência ou outro meio tecnológico), 246, V (citação por meio eletrônico), 270 (intimação por meio eletrônico), e, 319 (trouxe como requisito essencial da petição inicial, a necessidade de informação acerca do endereço eletrônico das partes), todos do CPC vigente, adotaram a agilidade tecnológica visando imprimir maior celeridade no trato processual.

Inconteste que esses avanços, de um lado, assusta-nos tamanha velocidade que as coisas acontecem no mundo virtual, mas, por outro lado, nos encanta com as facilidades e crescimento das informações, as quais, se bem utilizadas, contribuirão, positivamente, nos diversos ramos sociais e, especialmente, no âmbito jurídico.

\section{A TECNOLOGIA IMPACTANTE: GARANTIA DE ACESSO À JUSTIÇA}

Certo que a Constituição Federal de 1988 inaugurou um novo tempo no ordenamento jurídico brasileiro, quando passando pela mudança de Estado, saindo do autoritarismo para a democracia, trouxe um rol extenso de direitos e garantias fundamentais aos cidadãos brasileiros. Isso se estendeu a todo ordenamento, incluindo o processo civil, que passou também por algumas mudanças emblemáticas de concepção.

Para a adequação da nova sociedade que estava se formando, era necessário realizar a aproximação dessa população ao Poder Judiciário, já que o processo havia se tornado algo 
utópico para as pessoas comuns, em razão das grandes teorias e procedimentos idealizados pelos grandes processualistas da fase denominada de autonomista ou conceitual.

É importante ressaltar que o doutrinador italiano Mauro Cappelletti foi um dos grandes responsáveis pela mudança no processo civil, pois, com seus estudos, percebeu que os cidadãos que necessitavam da proteção do Estado-Juiz, tinham o direito de alcançar uma tutela jurisdicional célere, cumprindo adequadamente as noções de real e verdadeiro acesso à justiça e de um processo justo.

O Processualista desenvolveu, assim, as ondas renovatórias do processo, sendo, uma delas, exatamente a necessidade de se obter um processo mais simplificado, com teorias e conceituações mais acessíveis aos cidadãos comuns.

E, como o direito é parte intrínseca a sociedade, o direito deve acompanhá-la. É o que bem afirma Patricia Peck Pinheiro (2016, p. 76):

O que é certo é que a sociedade digital está evoluindo muito rápido e o Direito deve
acompanhar esta mudança, aprimorar-se, renovar seus institutos e criar novos
capazes de continuar garantindo a segurança jurídica das relações sociais, sob pena
de ficar obsoleto e isso estimular a prática da justiça com o próprio mouse e todas as
mazelas associadas ao uso arbitrário das próprias razões e ao desequilíbrio que pode
ser gerado pelo poder desmedido das grandes corporações que são as proprietárias
dos recursos que permitem a realização da vida digital.

Fazendo-se uma releitura da terceira onda renovatória instituída por Mauro Cappelletti e Bryant Garth (1988, p. 67/68), é aceitar que a tecnologia, com sua modernização de instrumentos e de mecanismos processuais permite verdadeiro acesso à justiça, sem limitar-se ao formalismo do acesso. Veja-se:

O novo enfoque de acesso à Justiça, no entanto, tem alcance muito mais amplo. Essa "terceira onda" de reforma [...] centra sua atenção no conjunto geral de instituições e mecanismos, pessoas e procedimentos utilizados para processar e prevenir disputas nas sociedades modernas.

Cada vez mais a esfera virtual invade o mundo real, seja como meio de prova, seja como ferramenta de efetivação de atos processuais, dentre eles intimações, chegando ao ápice de celebração de acordo em processo judicial por meio de vídeo conferência ou então homologação de acordo mediante tratativas em grupos criados pelo WhatsApp, baseando-se na ideia central de que a modernização e a adequação do ambiente judicial às tecnologias consistem na evolução do próprio Direito, contribuindo tanto para um processo mais célere e condizente com a necessidade do jurisdicionado, como para a adequação à nova geração que está se formando, que, inclusive, fará parte dos futuros operadores do direito. 


\section{TECNOLOGIA: MECANISMO DE REAL EFETIVIDADE E CELERIDADE PROCESSUAL}

Não há dúvidas que o Direito evolui na medida em que a sociedade e seus anseios também evoluem. Assim, nada mais justo que os meios de efetivação processual se modernizem e se adequem às constantes transformações do meio social, a fim de garantir e primar pela efetiva e célere resolução do conflito, bem como resguardar os direitos fundamentais protegidos pelo texto constitucional de 1988, inerentes a todo e qualquer ser humano.

Paulo Roberto de Figueiredo Dantas (2017, p. 24), assevera que "é por meio do processo, iniciado pelo direito de ação, que o cidadão pode se valer do Poder Judiciário para fiel observância dos direitos e garantias fundamentais".

Como pontuado anteriormente, as ondas renovatórias inauguradas pelos doutrinadores Mauro Cappelletti e Bryant Garth - muito influenciadas pela evolução social tecnológica - contribuíram, significativamente, para com as mudanças no modo de pensar, ver e simplificar o processo, objetivando o real e fácil acesso à justiça pelos cidadãos comuns.

E ao que parece, é neste sentido que o novo Código de Processo Civil é editado, aprovado e sancionado: dinamizando, facilitando, efetivando, a fim de tornar o processo célere e eficaz.

Nota-se que um dos objetivos do Código de Processo Civil de 2015 é o de primar pela resolução efetiva do mérito, de modo a reduzir as preocupações com exacerbados formalismos quando em detrimento do próprio cerne do conflito.

Não se pode esquecer, ainda, que, além da necessidade de solução do caso concreto, deve ser este solucionado em tempo razoável, para a real efetivação dos direitos ali pautados.

Assim, tem-se que o novo Código de Processo Civil inaugurou modelo expressamente constitucional de processo, com o precípuo objetivo de, realmente, garantir os direitos fundamentais dispostos no texto da Constituição Federal.

Nesse sentido leciona o doutrinador Humberto Theodoro Junior (2016, p. 10): “a nova orientação, dominada pelos ares do Estado Social de Direito, assume compromisso, a um só tempo, com a celeridade processual e com a justiça mais humana a ser proporcionada àqueles que clamam pela tutela jurídica”.

Como primeiro exemplo, dispôs-se expressamente no artigo $4^{\circ}$ do novo Código de Processo, o princípio constitucional da Duração Razoável do Processo (art. 5º LXXVIII, 
CRFB), incluído pela Emenda Constitucional n. 45/04, do qual decorre o princípio da Primazia da Resolução do Mérito: “Art. $4^{\circ}$. As partes têm o direito de obter em prazo razoável a solução integral do mérito, incluída a atividade satisfativa".

Alexandre Freitas Câmara (2017, p. 28) corrobora ao expor que "O processo é um método de resolução do caso concreto, e não um mecanismo destinado a impedir que o caso concreto seja solucionado".

Outro importante princípio expresso no artigo $6^{\circ}$ do texto processual de 2015 é o princípio da Cooperação, intimamente ligado aos princípios da Duração Razoável do Processo e da Primazia da Resolução do Mérito. Sendo fato que, sem sombra dúvidas, tal princípio nos remete a necessidade de inserção dos meios tecnológicos no âmbito processual civil como uma forma de cooperação, já que todos os seus sujeitos devem primar e cooperar para o fim precípuo de um processo, qual seja, seu resultado útil e célere.

A partir da ordem estabelecida, é importante destacar que o artigo $8^{\circ}$, do novel Código de Processo faz expressa menção ao princípio constitucional da Eficiência (art. 37, caput, da Constituição de Outubro, no sentido de que, quanto menos onerosidade no que tange aos meios de produção do resultado processual, mais eficiente será o processo (CÂMARA, 2017).

Esses princípios, dentre outros dispostos explícita ou implicitamente, irradiam sua força sobre todo o texto processual de 2015 , de forma a inaugurar ou aprimorar importantes mecanismos baseados nos meios tecnológicos, advindos das constantes evoluções sociais.

Como outrora explanado, importante exemplo está contido nos requisitos obrigatórios da petição inicial, dispostos no artigo 319 do NCPC, que, a despeito de outros tantos, expressa a necessidade de indicação do endereço eletrônico da parte. Aliás, frise-se que o anteprojeto do novo código de processo não previa tal disposição.

Admitamos: uma importante inovação, a qual caminha ao aprimoramento das comunicações dos atos processuais (arts. 236 a 275, CPC) e futuras e eventuais citações e intimações das partes por meios tecnológicos, por exemplo.

Sobre a comunicação dos atos processuais, dispõe o artigo 236 e $\$ 3^{\circ}$, do $\mathrm{CPC} / 2015$ :

Art. 236. Os atos processuais serão cumpridos por ordem judicial.

$\S 3^{\circ}$. Admite-se a prática de atos processuais por meio de videoconferência ou outro recurso tecnológico de transmissão de sons e imagens em tempo real.

Admitir a possibilidade de realização de videoconferências ou ainda de utilização de outros meios tecnológicos de transmissão de sons e imagens em tempo real, é também admitir 
positivamente que o processo deve aproveitar dos meios existentes, como os tecnológicos, a fim de alcançar a resolução do caso concreto dos cidadãos em tempo hábil e razoável.

É muito mais sensato admitir, por exemplo, que acordos sejam realizados por meio de videoconferências, quando uma das partes não pode comparecer pessoalmente, do que simplesmente extinguir o processo, sem resolver efetivamente o mérito, por conta de uma formalidade processual, isto é, porque a parte não pôde comparecer (por qualquer tipo de imprevisto, por exemplo). Esse é um exemplo concreto da tecnologia trabalhando conjuntamente com o Direito, e, por conseguinte, com o Poder Judiciário.

Do mesmo modo, quando da acareação de testemunhas, diz o $\S 2^{\circ}$ do artigo 461 do NCPC:

Art. 461. O juiz pode ordenar de ofício ou a requerimento da parte:

$\S 2^{\circ}$. A acareação pode ser realizado por videoconferência ou por outro recurso tecnológico de transmissão de sons e imagens em tempo real.

Nota-se que ambos os dispositivos supra mencionados, contém a idêntica e seguinte máxima "ou outro recurso tecnológico de transmissão de sons e imagens em tempo real", tratando-se de verdadeira disposição aliando a tecnologia ao Direito e ao Judiciário, trabalhando de modo a unir e dirimir fronteiras e facilitar o acesso à justiça aos cidadãos.

A título de elucidação, o Tribunal de Justiça do Estado de São Paulo vem utilizando um mecanismo de mediação e conciliação por videoconferência, oportunidade em que, havendo interesse de ambas as partes, agenda-se sessão por meio de programa especifico, presidido por um serventuário indicado pelo $\mathrm{CNJ}$, o qual dará oportunidade de as partes conversarem e se ajustarem. Em caso de acordo, a minuta será juntada pelo responsável da câmara no processo judicial, e, posteriormente será homologado pelo magistrado competente.

Não só a videoconferência, mas o aplicativo WhatsApp assume magnitude em nossa sociedade, já que relacionamentos são formados e dissolvidos, grupos são formados para diminuir distâncias entre familiares e amigos, para compartilhar anseios, desejos, notícias, materiais de estudo, de trabalho, reuniões são formadas e realizadas pelo aplicativo, dentre tantas outras positivas infinitas possibilidades ofertadas pelo uso da ferramenta.

Certo é que não se pode mais pensar no processo civil como meio de efetivação, celeridade e dinamização sem englobar os avanços tecnológicos, mormente quando tais avanços mostram-se como positivas ferramentas na construção de um processo civil mais simplificado e acessível aos cidadãos. 


\section{O USO DA TECNOLOGIA A FAVOR DO PROCESSO}

Se utilizada de forma positiva, sem dúvidas, a tecnologia será uma das maiores aliadas do processo, seja na seara cível, seja em qualquer outra seara do direito.

Nesse diapasão, necessário é citar um exemplo recente da conjunção "tecnologia e processo", que passou da mera possibilidade para a concretude, qual seja a realização de um acordo judicial por meio do aplicativo WhatsApp.

Conforme o termo homologado nos autos do processo de execução de créditos trabalhistas n. ${ }^{\circ}$ 0042200-22.1997.5.14.0031, o qual tramitou na $1^{\text {a }}$ Vara do Trabalho de Ariquemes no Estado de Rondônia, inúmeras foram as diligências realizadas a fim de satisfazer a execução, contudo sem sucesso.

Desse modo, quinze anos depois de iniciada a execução, isto é, no ano de 2018, surgiu a ideia de se criar um grupo no WhatsApp, onde, durante trinta dias, o acordo fora negociado entre as partes, seus advogados e a magistrada competente.

Nesse passo, estabeleceu-se no termo que a executada deveria pagar o montante de duzentos mil reais aos exequentes.

O mesmo ocorreu nos autos da Reclamação Trabalhista n. ${ }^{\circ}$ 000122320.2015.5.10.0111, que tramitava na $1^{\mathrm{a}}$ Vara do Trabalho do Gama no Distrito Federal. Cumpre frisar que, nesse caso, a audiência de conciliação fora realizada em exatos dez minutos, restando frutífera.

É de se notar que os exemplos mencionados ocorreram no âmbito do direito do trabalho, entretanto, há que se admitir que tais possibilidades mostram-se como meios extremamente positivos de celeridade e efetivação processual também na área civil.

Até porque, em que pese a divisão em ramos autônomos do direito, antes de tudo, o processo deve ser pensado em sua totalidade e principal objetivo, qual seja, a efetiva tutela jurídica dos direitos dos cidadãos.

Humberto Theodoro Junior (2016, p. 05) afirma que "muito íntimas são as relações do direito processual civil com os demais ramos do processo, como o processo penal, o trabalhista, o administrativo, etc., porquanto são apenas variações de um ramo maior, que é o direito processual."

Outra realidade tecnológica que se mostra cada vez mais presente na prática processual é a possibilidade de intimação pelo WhatsApp.

De acordo com dados fornecidos pelo Conselho Nacional de Justiça (CNJ), 
magistrados de pelo menos doze Tribunais de Justiça do país já utilizam o aplicativo para a intimação das partes do processo. Inclusive é pertinente ressaltar que esses tribunais estão empenhando-se cada vez mais em adquirir aparelhos celulares e capacitar seus funcionários para tanto.

Além disso, segundo o Conselho Nacional de Justiça, o WhatsApp não só está sendo utilizado para intimação de partes, como também para ouvir testemunhas residentes no exterior, em processos de violência contra a mulher e audiências de custódias, por exemplo.

Dentre os benefícios elencados pelos magistrados está a redução de custos, redução de stress e serviços dos servidores, facilidade na localização das partes, redução do constrangimento dos cidadãos, eficiência na prestação jurisdicional, redução da utilização de papel para o envio de cartas e o consequente benefício ao próprio meio ambiente, dentre outros.

De fato, não se pode mais olvidar do papel que os recursos tecnológicos assumiram na sociedade, e, por conseguinte, no Poder Judiciário e no processo como um todo. Aliar os corretos meios tecnológicos aos corretos meios de efetivação e celeridade processual é beneficiar a concreta efetivação dos direitos fundamentais dos cidadãos.

Ademais, tem-se que o novo Código de Processo Civil, amparado no Princípio da Adequação Processual, estabeleceu de forma expressa em seu artigo 190, a possibilidade de convenção processual, permitindo às partes estipular mudanças no procedimento, de forma a ajustá-lo às especificidades do processo, bem como convencionar sobre seus ônus, deveres, faculdades e poderes processuais, antes ou durante o processo.

É o chamado negócio jurídico processual. Mas o que o negócio jurídico processual tem a ver com o uso das tecnologias a favor do processo e da efetivação dos direitos?

Sugere-se, pois, mediante negócio jurídico processual, a possibilidade de inclusão de intimação das partes única e exclusivamente pelo WhatsApp, bem como de permissão de realização de acordos judiciais pelo mesmo aplicativo, ou ainda por meio de videoconferência, como bem permitida, esta última hipótese, pelo Código Processual Civil em seu artigo $236, \S 3^{\circ}$.

Ora, se o objetivo precípuo do processo é a efetiva tutela do direito, nada mais sensato do que permitir que as partes convencionem no âmbito processual sobre seus ônus, deveres, faculdades, poderes processuais, ajustem o procedimento às especificidades do processo, e, desse modo, convencionem, por exemplo, sobre como querem ser intimadas, 
visando a célere e efetiva resolução do mérito.

Nesse diapasão, Bruno Garcia Redondo assevera que (2016, p. 231):

É absolutamente essencial o rompimento com o anterior sistema, para que as novas premissas em que o NCPC se baseou possam ser observadas e, com isso, os novos institutos possam desfrutar do alcance e da amplitude que efetivamente merecem. O novo Código deve ser lido com novos olhos. Não há como caminhar para frente mirando-se o retrovisor.

Ainda, Bruno Garcia Redondo pontua (2016, p. 231):

Um Estado Democrático de Direito se consolida não com arbítrio e condutas contra legem, mas com a aplicação das normas expressamente positivadas pelo legislador. Ignorar-se a redação dos arts. 190 e 200 do NCPC, ou interpretar ditos dispositivos de forma a inviabilizar ou a restringir indevidamente a sua aplicação, será mais do que ilegal e inconstitucional: será antidemocrático.

Decerto se nota muito positiva a experiência do Poder Judiciário quando da implementação de recursos tecnológicos a favor do jurisdicionado, de modo a corroborar o espírito garantidor dos direitos instrumentais trazido pelo Código de Processo Civil de 2015 , tanto no que tange ao disposto em seu artigo $236, \S 3^{\circ}$, quanto no que tange a implementação - permitida pelo Conselho Nacional de Justiça - do aplicativo WhatsApp para, à título exemplificativo, realizar intimações, acordos judiciais e oitivas de testemunhas residentes no exterior.

\section{CONSIDERAÇÕES FINAIS}

De fato, ante todo o explanado, a partir da estruturação do Novo Código Processual concluiu-se que a possibilidade de implementação de ferramentas virtuais na conclusão de atos processuais, em especial de intimações e/ou notificações por intermédio de e-mails e do aplicativo WhatsApp mostra-se, por certo, positiva.

Não se pode mais olvidar em primeiro lugar, do papel que os recursos tecnológicos assumiram na sociedade, e, por conseguinte, no âmbito do Poder Judiciário e do processo pensado como um todo, e, em segundo lugar, da necessidade precípua de se garantir a proteção dos direitos e garantias fundamentais dos seres humanos a partir de sua efetiva tutela jurídica por meio de um processo célere e principalmente efetivo.

No âmbito processual civil, notou-se, ademais, a necessidade de aproximação do cidadão comum ao Poder Judiciário, já que em razão das grandes teorias e procedimentos dispostos pelos processualistas à época, o processo passou a mostrar-se como algo utópico 
para a população.

Felizmente o novo espírito do Código de Processo prestigia a evolução da tecnologia, inserindo em seu texto importantes inovações, tais como o artigo 319 que expressa a obrigatoriedade de indicação do endereço eletrônico da parte na petição inicial e o artigo 236, $\S 3^{\circ}$, o qual permitiu de forma expressa a realização de videoconferências e utilização de outros meios tecnológicos de transmissão de sons e imagens em tempo real.

Mencionando nesse ínterim que a utilização dos meios tecnológicos aliada ao âmbito do Judiciário, fora e é ensejadora de inúmeros benefícios, tais como a redução de custos, eficiência na prestação jurisdicional e a até mesmo redução no uso de papéis, com o consequente benefício ao meio ambiente.

\section{REFERÊNCIAS BIBLIOGRÁFICAS}

Acordo trabalhista realizado pelo WhatsApp. Disponível em: http://www.migalhas.com.br/Quentes/17,MI276165,21048-

Juiza+homologa+acordo+trabalhista+de+R+200+mil+firmado+em+grupo+de <acesso em 29/03/2018, às 15:00>

BARROSO, Luís Roberto. A segurança jurídica na era da velocidade e do pragmatismo. Disponível em: http://www.pge.go.gov.br/revista/index.php/revistapge/article/viewFile/102/86 <acesso em $18 / 03 / 18$, às 11:00>

BRASIL. Código de Processo Civil de 2015. In: Vade Mecum. 8. Ed. São Paulo: Revista dos Tribunais, 2016.

BRASIL. Constituição da República Federativa do Brasil de 1988. In: Vade Mecum. 8. Ed. São Paulo: Revista dos Tribunais, 2016.

CAPPELLETTI, Mauro. GARTH, Bryant. Acesso à justiça. Tradução Ellen Gracie Nrthfleet. Porto Alegre: Fabris. 1988.

CHIOVENDA, Giuseppe. Dell Azione Nascente dal Contratto Preliminare. 2.ed. Roma: Foro It, 1911.

CÂMARA, Alexandre Freitas. O Novo Processo Civil Brasileiro. São Paulo: Editora Atlas. 2016.

CINTRA, Antônio Carlos de Araújo; GRINOVER, Ada Pellegrini ; DINAMARCO, Cândido Rangel. Teoria geral do processo. 22. ed. São Paulo: Malheiros, 2006.

Cartilha de apresentação do Tribunal de Justiça digital. Disponível em: http://www.tjsp.jus.br/CemPorCentoDigital <acesso em: 26/03/2018>. 
Dados do Conselho Nacional de Justiça sobre o uso do WhatsApp. Disponível em: http://www.cnj.jus.br/noticias/cnj/86080-juizes-usam-whatsapp-para-auxiliar-atosprocessuais-em-11-estados-2 <acesso em 29/03/2018, às 14:00>.

DINAMARCO, Candido Rangel. A instrumentalidade do processo. 12. ed. São Paulo: Malheiros. 2005.

FEITOSA, Andréia Rocha. Apontamentos práticos do peticionamento eletrônico atual. In: Andréia Rocha Feitosa. Direito digital e modernização do judiciário. São Paulo: LTr. 2015.

JÚNIOR, Humberto Theodoro. Curso de Direito Processual Civil. Volume I. Rio de Janeiro: Forense, 2016.

MARINONI, Luiz Guilherme. Novas linhas do processo civil. 4. ed. São Paulo: Malheiros. 2000 .

MARINONI, Luiz Guilherme. ARENHART, Sérgio Cruz. MITIDIERO, Daniel. Novo código de processo civil comentado. 3. ed. São Paulo: Revista dos Tribunais, 2017.

NUNES, Rizzatto. Manual de introdução ao estudo do direito: com exercícios para sala de aula e lições de casa. 14. ed. São Paulo: Saraiva. 2017

PAESANI, Liliana Minardi. Direito de informática: comercialização e desenvolvimento internacional do software. 10. ed. São Paulo: Atlas. 2015.

PINHEIRO, Patricia Peck. Direito digital. 6. ed. São Paulo: Saraiva. 2016

REDONDO, Bruno Garcia. Negócios Jurídicos Processuais. In: WAMBIER, Luiz Rodrigues. WAMBIER, Tereza Arruda Alvim. Temas Essenciais do Novo CPC: Análise das principais alterações do sistema processual civil brasileiro de acordo com a Lei 13.256/2016. São Paulo: Revista dos Tribunais, 2016.

SILVA, José Afonso da. Constituição e Segurança Jurídica. In: ROCHA, Cármem Lúcia Antunes (coord.) Constituição e Segurança Jurídica: direito adquirido, ato jurídico perfeito e coisa julgada. Estudos em homenagem a José Paulo Sepúlveda Pertence. 2. ed. Belo Horizonte: Fórum, 2005.

SILVA, Ovídio A. Baptista da. Processo e ideologia: o paradigma racionalista. Rio de Janeiro: Forense, 2006. 